An Explosion Model Comparison with Insights from the Source Physics Experiments

S. R. Ford, W. R. Walter

January 14,2013

An Explosion Model Comparison with Insights from the Source Physics Experiments 
This document was prepared as an account of work sponsored by an agency of the United States government. Neither the United States government nor Lawrence Livermore National Security, LLC, nor any of their employees makes any warranty, expressed or implied, or assumes any legal liability or responsibility for the accuracy, completeness, or usefulness of any information, apparatus, product, or process disclosed, or represents that its use would not infringe privately owned rights. Reference herein to any specific commercial product, process, or service by trade name, trademark, manufacturer, or otherwise does not necessarily constitute or imply its endorsement, recommendation, or favoring by the United States government or Lawrence Livermore National Security, LLC. The views and opinions of authors expressed herein do not necessarily state or reflect those of the United States government or Lawrence Livermore National Security, LLC, and shall not be used for advertising or product endorsement purposes. 


\title{
An Explosion Model Comparison with Insights from the Source Physics Experiments
}

\author{
by Sean R. Ford and William R. Walter
}

\begin{abstract}
Seismic spectral models for chemical and nuclear explosions are used in many applications including network modeling and yield estimation. Here we compare the models presented in Denny and Johnson (1991) and Mueller and Murphy (1971) with each other and with new results from the Source Physics Experiments (SPE). We demonstrate analytically the two models are in substantial agreement for large and normally buried explosions, consistent with much of the historic data collected during nuclear testing. However for small and/or deeply buried explosions, the spectral predictions of the two models can differ significantly. For example, the predicted yield of a 1-km deep, $\mathrm{M}_{w} 2$ nuclear explosion differs by more than a factor of five, and for the same moment and depth chemical explosion, the difference is greater than a factor of ten. We compare the models with initial data from the Source Physics Experiments (SPE), which include small and overburied chemical explosions. The corner frequency of the one-ton SPE explosion (SPE-2) is slightly higher than the Mueller and Murphy (1971) model and approximately double the Denny and Johnson (1991) model prediction. The absolute moment of the one-tenth ton SPE explosion (SPE-1) is near the Denny and Johnson (1991) prediction and an order of magnitude smaller than the Mueller and Murphy (1971) prediction. The low-frequency moment ratio for SPE-2/SPE-1 is more consistent with the Denny and Johnson (1991) model. The results presented here show the need for an explosion source model that can accommodate a wider range of yields and emplacement conditions.
\end{abstract}

Supplemental Online Material: Figures of moment magnitude, corner frequency and yield for all geologic media.

\section{Introduction}

The ability to predict the expected seismic amplitudes from an explosion is important in a number of applications including exploration and nuclear test monitoring. An analytical model for P-waves was first developed by Sharpe (1942), based on pressure in a spherical cavity in an elastic medium. Since then a large number of explosion source spectral models have been developed based on empirical data and theoretical considerations (cf. Denny and Johnson, 1991). Such spectral models are used to determine network thresholds for nuclear test monitoring and to estimate source properties, such as yield and depth of burial from seismic data.

With the signing of the Comprehensive nuclear Test-Ban Treaty (CTBT) in 1996, and the cessation of testing by the signatories, any future nuclear tests may be conducted outside of standard practices and it is important to predict seismic observables for new regions and testing conditions. The development and validation of physics-based explosion models that extend the range of the current, more empirically, derived models is a focus of the DOE/NNSA funded Source Physics Experiments (SPE) (e.g. NNSA, 2012). The SPE focuses on physics-based model development work supported by a new chemical explosion dataset.

We focus here on two of the most widely used far-field explosion P-wave spectral models: Mueller and Murphy (1971), hereafter referred to as MM, and Denny and Johnson (1991), hereafter referred to as DJ. MM developed a spectral model for several different emplacement media as a function of depth and source size. They extended the Sharpe (1942) analytical elastic response and developed a new pressure function applied at the elastic radius (distance from the source where the media begins to respond elastically) that 
was consistent with a wide variety of seismic free field data collected from nuclear tests. DJ take a different approach, regressing both chemical and nuclear explosion data to determine expressions for far field spectral parameters such as seismic moment and corner frequency.

While the variety of explosion models that were developed over time indicates a certain level of uncertainty in the accuracy of their predictions, we show here that the model differences may be greater than commonly understood for small and/or over-buried explosions. Typical scale depths of burial for the former Nevada Test Site are approximately $120 \mathrm{~m} / \mathrm{kt}^{1 / 3}$ (e.g. OTA, 1989), while over-buried tests have larger scale depths of burial. Recently numerical model results have also indicated some differences with the historical models. For example Rougier et al. (2011) showed that historical cavity radius models don't fit numerical modeling for over-buried shots. Hydrodynamic calculations for 1-5 kt explosions in granite performed by Xu et al (2012) show higher corner frequencies and different low-frequency moment scaling with depth than MM and DJ.

In this paper we first compare the two explosion models analytically, writing out expressions for moment, corner frequency and yield for each model in terms of emplacement conditions. Then we show graphically how they compare for a wide variety of yields and depths of burial, indicating very large differences for small and/or over-buried explosions. Finally we compare the models with initial data from the first two SPE chemical explosions, which are over-buried. The results show neither model matches the SPE data as well as desired.

\section{Explosion Models}

Denny and Johnson (1991) regressed a large amount of chemical and nuclear data to build their models. DJ start with a regression for cavity radius $R_{c}$ and relate it to measured moment $M_{0}$ via a ratio to theoretical moment $\left(\frac{4}{3} \pi \rho \alpha^{2} R_{c}^{3}\right)$ to obtain:

$$
M_{0}^{D J}=4.2743 \times 10^{10} W \alpha^{2} \beta^{-1.1544} P^{-0.4385} 10^{-0.0344 G P} \rho,
$$

where $M_{0}$ is in N-m and $W$ is yield (kt), $\beta$ is shear velocity (m/s), $P$ is the overburden pressure (Pa) and is equal to $\rho_{0} g h$ where $\rho_{0}$ is the overburden density (average density to shot point in $\left.\mathrm{kg} / \mathrm{m}^{3}\right), g$ is gravity $(9.8067$ $\left.\mathrm{m} / \mathrm{s}^{2}\right)$ and $h$ is the DOB (m), GP is the gas-porosity (\%), $\rho$ is the shot-point density $\left(\mathrm{kg} / \mathrm{m}^{3}\right)$ and $\alpha$ is compressional velocity $(\mathrm{m} / \mathrm{s})$.

They also relate cavity radius to the source radius defined as $\beta / \pi f_{c}$ so that the corner frequency $f_{c}$ is given by:

$$
f_{c}^{D J}=0.2045 W^{-1 / 3} \beta^{-0.0642} P^{0.5522} 10^{0.0025 G P} \rho^{-0.7245},
$$

where $f_{c}$ is in Hz. Finally, Johnson (1994) rearranged the DJ relations to find yield, W:

$$
W^{D J}=2.940 \times 10^{-10} \beta^{1.1544} P^{0.4385} 10^{0.0344 G P} \Psi_{\infty},
$$

where $\Psi_{\infty}$ is the static reduced displacement potential $\left(\mathrm{m}^{3}\right)$ which is equal to $M_{0} / 4 \pi \rho \alpha^{2}$.

Mueller and Murphy (1971) assume scaling in amplitude and yield and produce empirical constants to calculate the spectra for various media. Stevens and Day (1985) interpret the constants for a set of standard media given in Murphy (1977) and derive the seismic moment from the long-period limit of the reduced displacement potential to get

$$
M_{0}^{M M}=3.1416 W^{0.87} \alpha^{2} \beta^{-2} R_{0}^{3} P_{0} h_{0}^{1 / 3} h^{-1 / 3},
$$

where $P_{0}, h_{0}$, and $R_{0}$ are empirical constants for different media and are given in Table 1 from Stevens and Day (1985). 
The elastic radius is inversely proportional to source corner frequency so that

$$
f_{c}^{M M}=0.1592 W^{-1 / 3} \alpha R_{0}^{-1} h_{0}^{-1 / n} h^{1 / n}
$$

given in $\mathrm{Hz}$, where $n$ is another empirical constant for a given media and is stated in Table 1. Finally, the Stevens and Day (1985) relations can be inverted to find yield as a function of static reduced displacement potential,

$$
W^{M M}=4.9207 \rho^{1.1494} \beta^{2.2989} R_{0}^{-3.4483} P_{0}^{-1.1494} h_{0}^{-0.3831} h^{0.3831} \Psi_{\infty}^{1.1494} .
$$

\section{Model Comparison for Canonical Media}

We compare the source parameters, seismic moment and corner frequency, derived from MM and DJ using the four canonical media parameters given in Table 1. Stevens and Day (1985) state that these are the parameters used in deriving the empirical constants also given in Table 1.

In order to compare with the DJ model, which additionally requires $G P$ and $\rho_{0}$ (via $P$ ), we reference Springer (1966) for GP and assume that overburden density is approximately equal to shot-point density at the depths investigated in this study. As we show later, the results aren't too sensitive to this assumption. Figure 1a shows the DJ- and MM-predicted moment magnitude $M_{W}\left(M_{W}=0.6667 \log _{10}\left(M_{0}\right)-6.0633\right)$ as a function of burial depth and yield for the granite model. Figure $1 \mathrm{~b}$ shows the difference in the predictions. At the standard containment practice of scaled depth of burial (sDOB) of $\sim 120 \mathrm{~m} / \mathrm{kt}^{1 / 3}$ for shots $>20 \mathrm{kt}$, the difference is $<0.1$ magnitude unit. However, for over-buried (e.g. sDOB $\geq 1000 \mathrm{~m} / \mathrm{kt}^{1 / 3}$ ) small $(<1 \mathrm{kt}$ ) explosions the difference is $>0.2$ magnitude units.

Figure 2a shows the DJ-predicted corner frequency in Hertz as a function of burial depth and yield for the granite model. Since both models contain cube-root yield scaling $\left(f_{c} \sim 1 / W^{1 / 3}\right)$ their ratio is not dependent on yield and we can plot their ratio versus DOB as is done in Figure 2b. Since MM was built with nuclear data only, we also show a comparison where the yield for MM is doubled as is predicted by chemical/nuclear equivalency studies (Denny, 1994) and numerical calculations (e.g., Xu et al., 2012). Note that DJ was built using both chemical and nuclear data, and DJ state "no evidence was found in this study to suggest that chemical and nuclear explosions are significantly different," so no change is made to the DJ model for chemical explosions.

We can take the ratio of eqs (3) and (6) to examine the nuclear yield difference between the DJ and MM models as a function of seismic moment and depth. This ratio is given by

$$
\frac{W^{D J}}{W^{M M}}=\frac{2.940 \times 10^{-10} \Psi \beta^{1.1544} P^{0.4385} 10^{0.0344 G P}}{4.9207 \Psi^{1.1494} \beta^{2.2989} \rho^{1.1494} h^{0.3831} h_{0}^{-0.3831} P_{0}^{-1.1494} R_{0}^{-3.4483}}
$$

If we assume the shot point density is equal to the overburden density in $P$ then we can reduce eqn (7) in terms of depth of burial and seismic moment to

$$
\frac{W^{D J}}{W^{M M}}=F \frac{h^{0.0554}}{M_{0}^{0.1494}}
$$

where $F$ is a medium dependent constant given by

$$
F=8.552 \times 10^{-10} 10^{0.0344 G P} h_{0}^{0.3831} P_{0}^{1.1494} R_{0}^{3.4483} \alpha^{0.2988} \beta^{-1.1445} \rho^{-0.5615} .
$$

$F$ for the canonical media is given in Table 1 . Figure 3 shows this yield ratio of the differences between the models as a function of depth of burial and moment magnitude

The models are most disparate for small magnitude explosions and great depth. For example, the DJ yield prediction for a $\mathrm{M}_{\mathrm{W}}=2$ at $1 \mathrm{~km}$ depth is $\sim 10$ tons (black line, Figure $3 \mathrm{a}$ ), which is $\sim 5 \frac{1}{2}$ times greater than 
the MM nuclear yield prediction (Figure $3 \mathrm{~b}$ ). If the comparison is made for a chemical explosion, the yield ratios in Figure $3 \mathrm{~b}$ should be multiplied by a chemical/nuclear yield scaling factor to account for the nuclearderived MM model, and no change is needed for the DJ model since it makes no chemical/nuclear distinction. For example, if the scaling factor is two as mentioned above, the MM chemical yield estimate for a $M_{W}=2$ is $\sim 11$ times smaller than DJ estimate of 10 tons at $1 \mathrm{~km}$ depth.

\section{Model Comparison with the Source Physics Experiment}

The Source Physics Experiments (SPE) at the Nevada National Security Site (NNSS) are a series of chemical explosions intended to enhance our physical understanding and ability to quantitatively model seismic signals from explosions with the goal of improving nuclear test monitoring capabilities (NNSA, 2012, Snelson et al., 2012). These tests are sponsored by the U.S. Department of Energy, National Nuclear Security Administration's National Center for Nuclear Security. The SPE offers a chance to examine explosion seismic signals generated at a wider variety of depths and geologies than exists for local and regional distance nuclear test data. The first SPE explosions took place in the granitic rock of the Climax Stock, in northern Yucca Flat (Figure 4 and Table 2).

All shots were recorded on a local network of geophones and intermediate period seismometers deployed along radial lines at five different azimuths. The raw waveforms of SPE- 1 and -2 recorded at the nearest intermediate period stations along Lines $1-4$ at $2 \mathrm{~km}$ and along Line 5 at $1.6 \mathrm{~km}$ (no Line 5 station at 2 $\mathrm{km}$ ) are given in Figure 5. Low-frequency band-pass filtered traces from SPE-2 are given in Figure 6. The close proximity and smaller size of SPE-1 allows it to be used as an empirical Green function or transfer function for the SPE-2 data to eliminate path effects on the observed spectra. Note that in using the transfer function (ratio of SPE-2/SPE-1) any chemical/nuclear scale factor is in common and drops out. A similar approach was taken by Denny (1998) to investigate the corner frequencies of the Kazakhstan Depth of Burial Experiment (KDOBE), where he found DJ-predicted corner frequencies to be lower than observed.

We use two seconds of data recorded on the intermediate period sensor and calculate the transfer function (ratio of SPE-2/SPE-1) between SPE-1 and SPE-2 with the multitaper spectral measurement package, mtspec (Prieto et al., 2009). Figure 7 shows the SPE-2/SPE-1 transfer function estimated for each component along each line at $2 \mathrm{~km}$, and at $1.6 \mathrm{~km}$ on Line 5 , along with predictions for the ratio in the longperiod limit. DJ-predicted long-period ratios are given by the ratio of yields and MM-predicted ratios are given by the ratio of yields to the power of 0.87 . The predicted corner frequencies of the large shots are also plotted where we have to assume near-source parameters, which are given in Table 2, and a chemical/nuclear yield scale factor of two for MM. The long-period ratio of the data falls close to the DJpredicted value and is greater than the MM prediction. The observed SPE-2 corner frequency is significantly larger than the DJ prediction and only slightly higher than the MM prediction. If the observed corner frequency were used with the DJ model to estimate the depth of the explosion, it would be significantly overestimated.

The log-average of the SPE-2/SPE-1 transfer function is plotted in Figure 8, along with the predicted MM and DJ spectral ratios, where the DJ spectra are assumed to have a Brune-like shape (low-frequency limit and high-frequency fall-off proportional to frequency-squared) with long-period limit and corner frequency defined by the models. Townsend et al. (2012) report a range of near-source parameters for different measurement methods and agencies. Given this uncertainty, we calculate the transfer function SPE2/SPE1 ratio for the whole range of values of compressional velocity, shear velocity, density, and porosity of 4700 to $5928 \mathrm{~m} / \mathrm{s}, 2900$ to $3700 \mathrm{~m} / \mathrm{s}, 2635$ to $2670 \mathrm{~m} / \mathrm{kg}^{3}$, and 0.7 to $3.2 \%$, respectively. The range of transfer functions is plotted as the gray-shaded region in Figure 8. These variations only affect the SPE2/SPE1 corner frequency, where DJ ranges from 9.0 to $9.4 \mathrm{~Hz}$ and the MM from 12.3 to $15.7 \mathrm{~Hz}$. As eqn (2) shows, the DJ model is not as dependent on near-source velocity. Again, the observed low frequency or moment level is close to the DJ prediction and significantly above the MM prediction, but the DJ model under-predicts the corner frequency.

In order to understand the absolute predictions of both models we create synthetic explosion recordings (with the program FKRPROG [Saikia, 1994]) and compare them with low-frequency recordings on intermediate-period 3-component seismometers. We compare with SPE-1 since the discrepancy in the models is most evident for small explosions at great depths (Figure 1). $W$ is directly related to $M_{0}$ and displacement is proportional to moment-rate, where we assume a static moment and a point-source, which is 
appropriate at these low-frequencies. We create synthetics for three simple one-dimensional velocity models (Table 3). Velocity model 1 is a simple weathered layer over granite derived from data presented in Townsend et al. (2012). Velocity model 2 is from the study of Rowe et al. (2012) and velocity model 3 is from the Rg dispersion work of Patton (2012).

We compare the radial and vertical waveforms predicted for the near-source parameters given by the models for DJ-predicted seismic moment with the data at the station on Line 5 in Figure 9 and with MMpredicted moment in Figure 10, where a chemical/nuclear scale factor of two is applied. The seismic moments for each velocity model and prediction are given in Table 3 . While there are some small differences in the phase, the amplitudes for the DJ model in Figure 9 are in reasonable agreement with the data for all of the velocity models. In contrast the MM amplitudes in Figure 10 are much larger than observed. We note that the near-source velocities in Models 2 and 3 are below the range presented in Townsend et al. (2012), and the MM-predicted waveforms from these models are even larger those from Model 1. These results indicate the low frequency MM mismatch with the observations holds even given the uncertainties in the velocity models. If the MM model were used to estimate the chemical yield from the observed SPE-1 low frequency level, it would over-estimate the yield by greater than a factor of ten. While the DJ model matches the chemical explosion moment level, its lack of a chemical/nuclear scale factor means it likely would over-predict small nuclear test data, assuming the chemical/nuclear factor of about two observed in the 1993 NPE 1 kt chemical explosion applies for the SPE yields and depths. Similar results were found by a preliminary analysis of the KDOBE with absolute moments in agreement with Patton et al. (2005).

Finally we note that there is significant energy on the transverse components at all stations shown in Figure 6, which is not predicted by any isotropic explosion model. With the exception of the station at Line 3, which lies along a geologic contact, the low-passed radial and vertical component data are similar in amplitude and phase. An improved physical understanding of the relative contributions to the transverse energy from near-source effects, free-surface interactions (e.g. spall) and far-field scattering/conversions is a major goal of the SPE and the subject of future work.

\section{Conclusions}

The DJ (Denny and Johnson, 1991) and MM (Mueller and Murphy, 1971) explosion source models predict similar P-wave spectra for large (>20 kt) explosions at normal scaled depth of burial $\left(\sim 120 \mathrm{~m} / \mathrm{kt}^{1 / 3}\right)$, but deviate from each other significantly for small and or over-buried explosions. Consequently, estimates of yield from observed data or determinations of monitoring network thresholds would be significantly different for small and/or overburied explosions depending upon which model was used. For example, the predicted yield of a 1-km deep, $\mathrm{M}_{\mathrm{W}} 2$ nuclear explosion differs by more than a factor of five, and the same moment and depth chemical explosion results in a difference greater than a factor of ten. DJ underestimates the observed corner frequencies of the SPE- 2 chemical explosions by about a factor of two, while the observed moment of SPE-1 is overestimated by an order of magnitude by MM. The observed moment ratio of SPE-2/SPE-1 are more consistent with the DJ model. For the DJ model, its mixing of chemical and nuclear data without the chemical/nuclear scale factor of about two observed in the 1993 NPE, indicate DJ would likely overpredict small nuclear moment and yield values. The large differences between these explosion source models and the SPE data for small and/or over-buried explosions, together with the lack of models to predict S-wave and Rayleigh observations, point to the need to develop new explosion models valid for a wider range of yield and emplacement conditions.

\section{Data and Resources}

The SPE project is following an IRIS PASSCAL two-year data hold policy and then plans to make the data widely available.

\section{Acknowledgements}


We thank NNSA for funding this research and gratefully acknowledge the staff at NSTec, UNR, DTRA, LANL, SNL and LLNL that carried out the SPE, providing the key data used in this paper. We are very grateful to Rob Mellors for his work in quality control of the SPE data and a review of this manuscript. We are grateful for an internal review by Steve Myers. We thank Howard Patton for discussions on explosion models and scaling over the course of the SPE. This work was performed under the auspices of the U.S. Department of Energy by Lawrence Livermore National Laboratory under Contract DE-AC52-07NA27344. LLNL-JRNL-609992. 


\section{References}

Denny, M. D. and L. R. Johnson (1991). The explosion seismic source function: Models and scaling laws reviewed, in Explosion Source Phenomenology, eds. Taylor S. R. et al., AGU Monograph 65: 1-24.

Denny, M. D. (1994). Introductions and highlights, in Proceedings of the Symposium on the Non-Proliferation Experiment Results and Implications, M. D. Denny et al. (eds.), Lawrence Livermore National Laboratory, Livermore, CONF-9404100.

Denny, M. (1998). Seismic-source corner frequencies from the Depth of Burial Experiment, Lawrence Livermore National Laboratory, UCRL-ID-132296.

Johnson, L. R. (1994). Seismic source parameters, in Proceedings of the Symposium on the Non-Proliferation Experiment Results and Implications, M. D. Denny et al. (eds.), Lawrence Livermore National Laboratory, Livermore, CONF-9404100.

Mueller, R. A. and J. R. Murphy (1971). Seismic characteristics of underground nuclear detonations, Part I: Seismic spectrum scaling, Bull. Seismol. Soc. Am. 61: 1675-1692.

NNSA Press Release, 2012. Available at: http://nnsa.energy.gov/mediaroom/pressreleases/spe3072412

National Nuclear Center (NNC) of the Republic of Kazakhstan, 1996. Unused vertical boreholes at the Balapan test field of the former Semipalatinsk test site, Technical Field Report, Kurchatov City, Republic of Kazakhstan, p. 40.

Office of Technology Assessment (OTA) US. Congress, (1989). The Containment of underground nuclear Explosions, OTA-ISC-414, U.S. Government printing office, Washington , D.C. Available at : http://www.fas.org/ota/reports/8909.pdf

Patton, H. J., J. L. Bonner, and I. N. Gupta (2005). Rg excitation by underground explosions: Insights from source modeling the 1997 Kazakhstan depth-of-burial experiment, Geophys. J. Int., 163, 1006-1024, doi: 10.1111/j.1365-246X.2005.02752.x.

Patton, H. (2012). Have the effects of material damage been detected in Rg waveforms recorded on SPE-1 and -2?, Los Alamos National Laboratory, LA-UR-12-22068.

Phillips, W. S., D. C. Pearson, C. L. Edwards, D. F. Baker and M. D. Denny (1998). Near source recording of the Depth of Burial Experiment at Shagan River, Kazakhstan: Data report, Lawrence Livermore National Laboratory, UCRL-ID-131199.

Prieto, G. A., R. L. Parker, F. L. Vernon. (2009), A Fortran 90 library for multitaper spectrum analysis, Computers and Geosciences, 35, pp. 1701-1710. doi:10.1016/ j.cageo.2008.06.007.

Rowe, C. A., H. J. Patton, X. Yang, and E. Rougier (2012) Seismic Body Wave Velocities Derived from SPE P-Wave Travel Times and Rg Phase Velocity Dispersion - Time Domain and Frequency Domain Methods, Seis. Soc. Amer. Ann. Meeting, San Diego, CA.

Rougier, E., H. J. Patton, E. E. Knight, and C. R. Bradley (2011). Constraints on burial depth and yield of the 25 May 2009 North Korean test from hydrodynamic simulations in a granite medium, Geophys. Res. Lett., 38, doi:10.1029/2011gl048269.

Saikia, C. K. (1994). Modified frequency-wavenumber algorithm for regional seismograms using Filon's quadrature; modelling of Lg waves in Eastern North America, Geophys. J. Int., 118(1), 142-158.

Sharpe, J. A. (1942). The production of elastic waves by explosion pressures: I, Theory and Empirical field observations, Geophysics 7 , 144-154.

Snelson et al. SPE EOS article in progress

Stevens, J. and S. M. Day (1985). The physical basis of mb:Ms and variable frequency magnitude methods for earthquake/explosion discrimination, J. Geophys. Res., 90 (B4), 3009-3020.

Springer, D. L. (1966). P-wave coupling of underground nuclear explosions, Bull. Seis. Soc. Amer., 56 (4), 861-876.

Townsend, M., L. B. Prothro, and C. Obi (2012). Geology of the Source Physics Experiment site Climax Stock Nevada National Security Site, DOE/NV/25946-1448.

Xu, H., A. J. Rodgers, I. N. Lomov, and O. Y. Vorobiev (2012). Seismic source characteristics of nuclear and chemical explosions in granite from hydrodynamic simulations, Pure Appl. Geophys., doi: 10.1007/s00024-0120-0623-0.

Walter, W. R, K. D. Smith, J. L. O’Boyle, T. F. Hauk, F. Ryall, S. D. Ruppert, S. C. Myers, R. Abbot, and D. A. Dodge (2004). An assembled western United States dataset for regional seismic analysis, Lawrence Livermore National Laboratory document, UCRL-TR206630 . 
Table 1. MM71 empirical constants and parameters from Stevens and Day (1985) via Murphy (1977)

\begin{tabular}{lllllllllr}
\hline Media & $P_{0}[\mathrm{~Pa}]$ & $h_{0}[\mathrm{~m}]$ & $R_{0}[\mathrm{~m}]$ & $n$ & $\alpha[\mathrm{m} / \mathrm{s}]$ & $\beta[\mathrm{m} / \mathrm{s}]$ & $\rho\left[\mathrm{kg} / \mathrm{m}^{3}\right]$ & $G P[\%]^{\#}$ & $F^{+}$ \\
\hline Tuff/Rhyolite & $5.0 \times 10^{6}$ & 122 & 202 & 2.40 & 3500 & 2021 & 2000 & 6 & 1021 \\
Granite & $2.4 \times 10^{6}$ & 122 & 321 & 2.40 & 5500 & 3175 & 2550 & 1 & 869 \\
Salt & $0.8 \times 10^{6}$ & 122 & 478 & 1.87 & 4670 & 2696 & 2200 & 0.5 & 1085 \\
Shale & $2.5 \times 10^{6}$ & 122 & 265 & 2.40 & 4320 & 2495 & 2350 & 0.5 & 1116 \\
\hline
\end{tabular}

\# from Springer (1966)

+ see eqn (9)

Table 2. SPE near-source parameters (from Townsend et al., 2012)

\begin{tabular}{llllllll}
\hline Shot & Depth $[\mathrm{m}]$ & $\alpha[\mathrm{m} / \mathrm{s}]$ & $\beta[\mathrm{m} / \mathrm{s}]$ & $\rho\left[\mathrm{kg} / \mathrm{m}^{3}\right]$ & $G P[\%]^{*}$ & SHANFO $^{1}[\mathrm{lbs}]$ & $W\left[\right.$ TNNT-equivalent $\left.^{2} \mathrm{~kg}\right]$ \\
\hline SPE-1 & 54.9 & 5900 & 3600 & 2630 & 1 & 220.92 & 85.17 \\
SPE-2 & 45.7 & 5900 & 3600 & 2630 & 1 & 2571.96 & 991.63 \\
\hline
\end{tabular}

* Assumed values

${ }^{1}$ Sensitized Heavy Ammonium / Nitrate Fuel Oil

${ }^{2}$ SHANFO $/$ TNT $=0.85($ ARA, 2012)

Table 3. SPE 1-D velocity models

\begin{tabular}{llllllllll}
\hline Name & Source & $\begin{array}{l}\text { Thick } \\
{[\mathrm{m}]}\end{array}$ & $\begin{array}{l}\alpha \\
{[\mathrm{m} / \mathrm{s}]}\end{array}$ & $\begin{array}{l}\beta \\
{[\mathrm{m} / \mathrm{s}]}\end{array}$ & $\begin{array}{l}\rho \\
{\left[\mathrm{kg} / \mathrm{m}^{3}\right]}\end{array}$ & $Q_{\alpha}$ & $Q_{\beta}$ & $\begin{array}{l}M_{0} \mathrm{DJ} \\
{[\mathrm{nAk}]}\end{array}$ & $\begin{array}{l}M_{0}^{\mathrm{MM}} \\
{[\mathrm{nAk}]} \\
\left(W_{\text {SPE-1 }} \mid 2 \times W_{\text {SPE-1 }}\right)\end{array}$ \\
\hline Model 1 & Townsend et al. (2012) & 13.7 & 4500 & 2900 & 2610 & 300 & 150 & 48.5 & $251.7 \mid 460.1$ \\
& & $\infty$ & 5900 & 3600 & 2630 & 600 & 300 & & \\
Model 2 & \multirow{2}{*}{ Rowe et al. (2012) } & 5.5 & 750 & 375 & 2300 & 150 & 75 & 52.5 & $373.3 \mid 682.3$ \\
& & 5.5 & 1050 & 525 & 2300 & 150 & 75 & & \\
& & 9 & 2500 & 1389 & 2500 & 300 & 150 & & \\
& & 450 & 4750 & 2380 & 2800 & 600 & 300 & & \\
Model 3 & Patton (2012) & $\infty$ & 6500 & 4200 & 2800 & 600 & 300 & & \\
& & 22 & 1300 & 700 & 2580 & 200 & 100 & 44.8 & $306.3 \mid 559.7$ \\
\hline
\end{tabular}

Note: $1 \mathrm{Ak}=10^{18} \mathrm{~N}-\mathrm{m}$ 

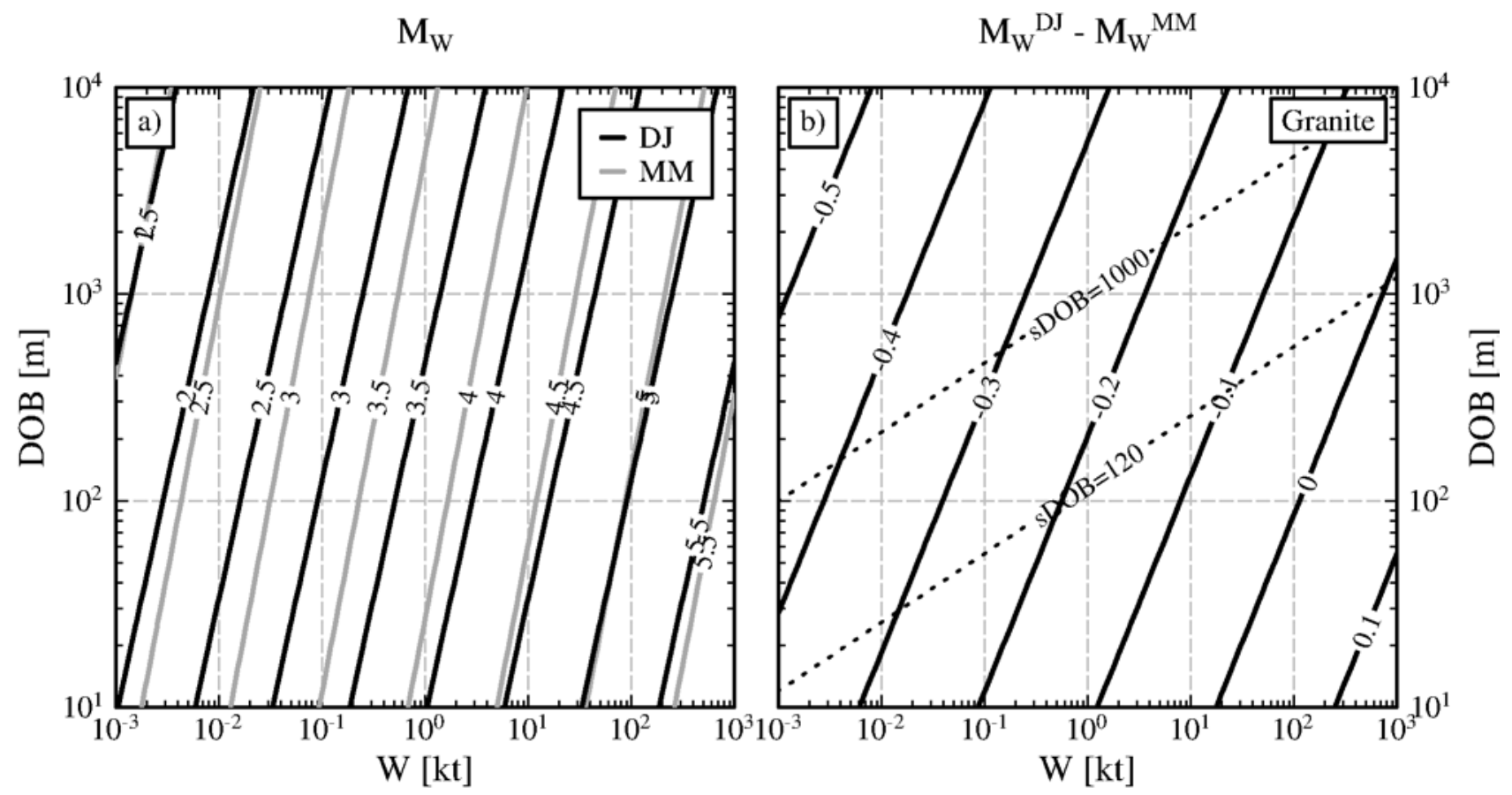

Figure 1 (m2). a) DJ- and MM-predicted nuclear explosion $M_{W}$ (black and gray lines, respectively) for the granite model (see Table 1) as a function of depth of burial (DOB) and yield (W). b) $M_{W}$ difference between DJ and MM nuclear predictions for granite model (see Table 1) as a function of depth of burial (DOB) and yield (W) where scaled DOB (sDOB) contours (dotted lines) for standard burial practice $\left(\sim 120 \mathrm{~m} / \mathrm{kt}^{1 / 3}\right)$ and overburied explosions $\left(\sim 1000 \mathrm{~m} / \mathrm{kt}^{1 / 3}\right)$ are also plotted. 


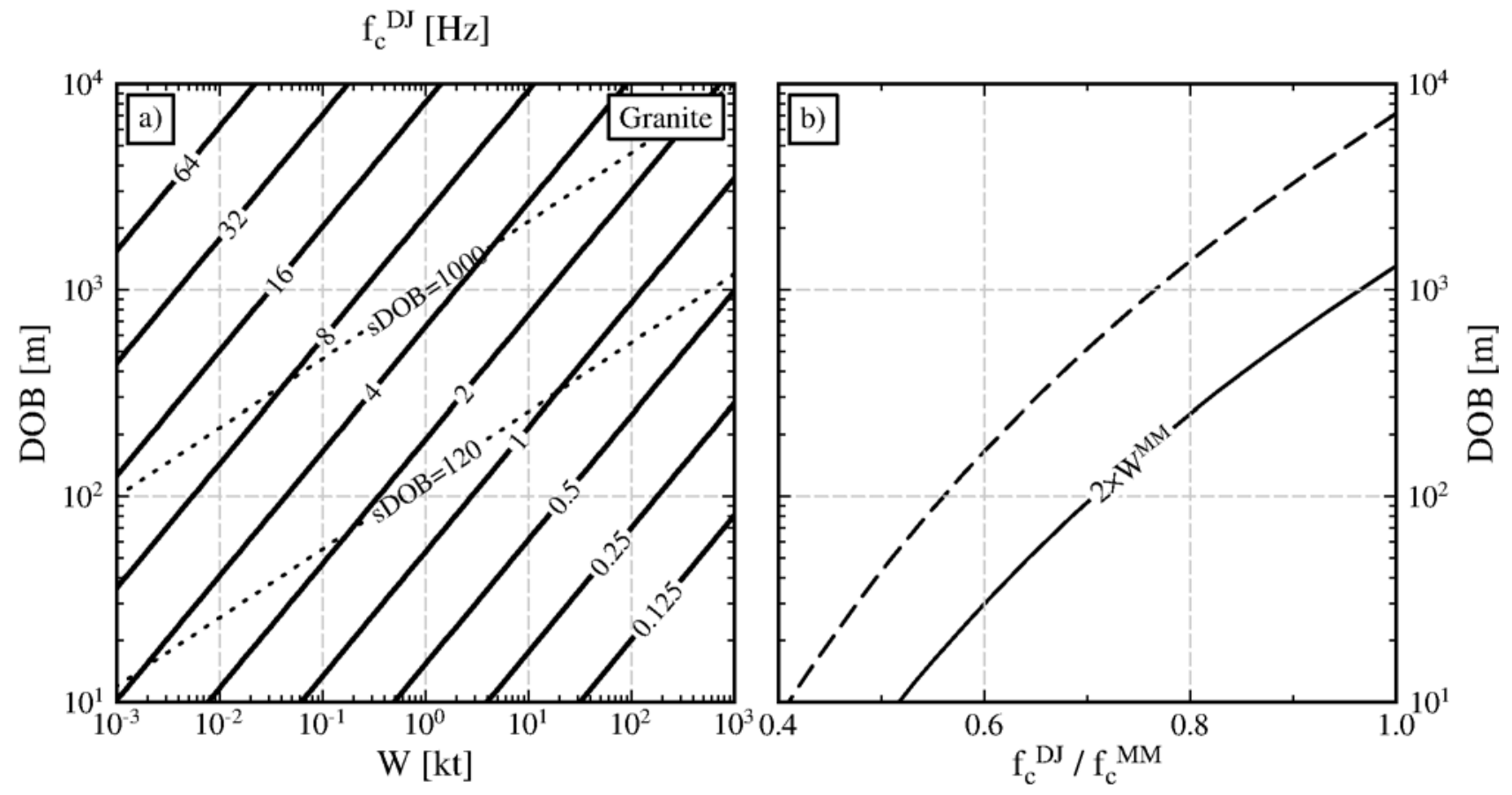

Figure 2 (f). a) DJ-predicted explosion $f_{c}$ in hertz for the granite model (see Table 1) as a function of depth of burial (DOB) and yield (W) where scaled DOB (sDOB) contours for standard burial practice $\left(\sim 120 \mathrm{~m} / \mathrm{kt}^{1 / 3}\right)$ and over-buried explosions ( $\left.1000 \mathrm{~m} / \mathrm{kt}^{1 / 3}\right)$ are also plotted. b) Ratio of DJ- to MM-predicted nuclear explosion $f_{c}$. Since both models have cube-root yield dependence their ratio is only a function of DOB. Solid line is the ratio for chemical explosions where for MM the chemical/nuclear yield factor is two, while the DJ model is the same for chemical and nuclear explosions. 
$\mathrm{W}$ [kt]

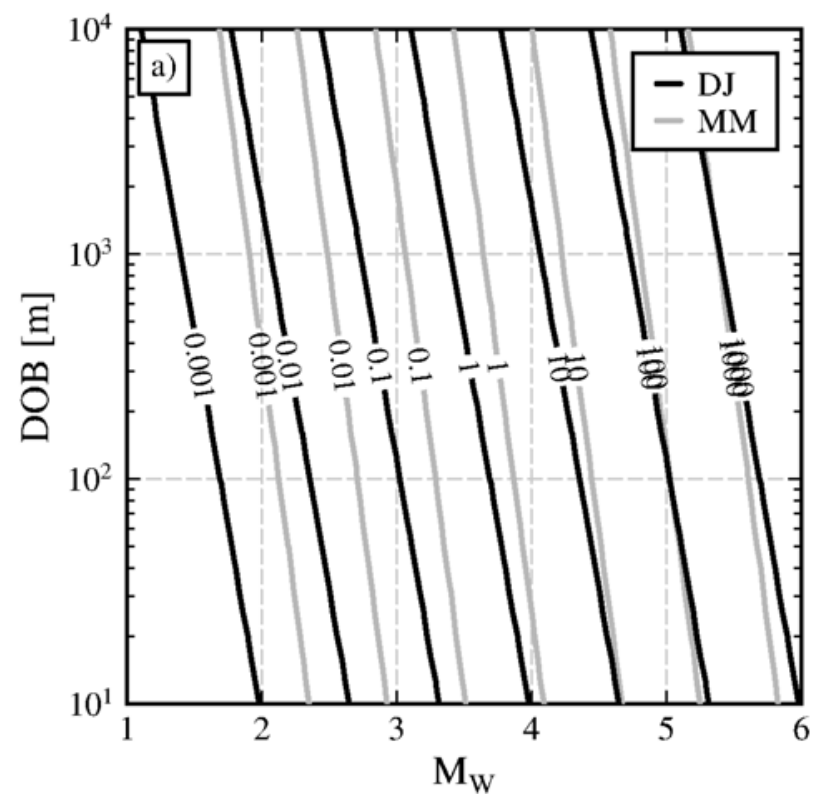

$\mathrm{W}^{\mathrm{DJ}} / \mathrm{W}^{\mathrm{MM}}$

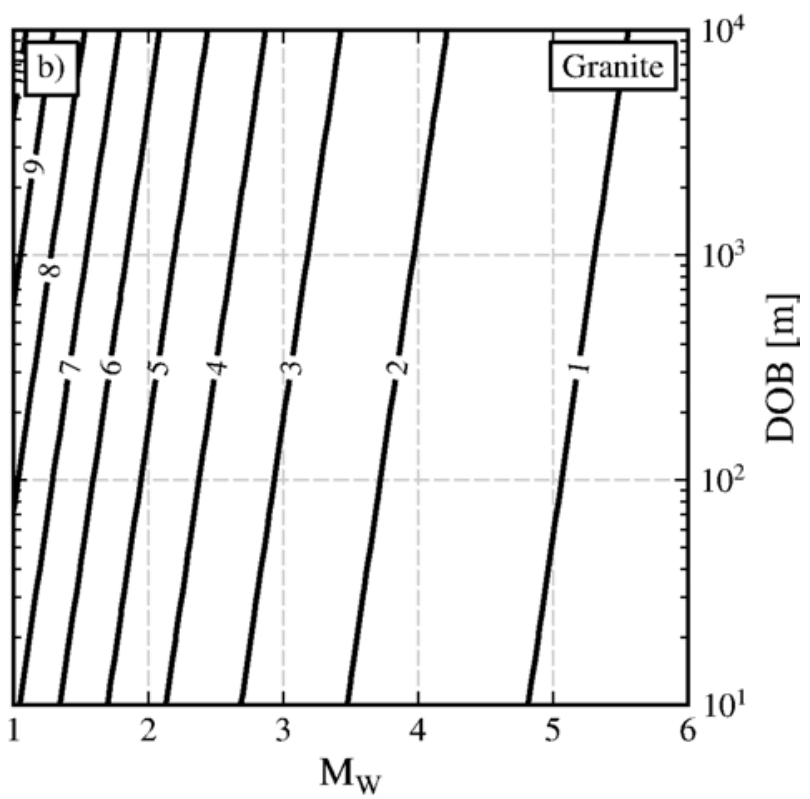

Figure $3(\mathbf{w})$. a) DJ- and MM-predicted yield $(W)$ in kt (black and gray lines, respectively) for the granite model (see Table 1) as a function of depth of burial (DOB) and moment magnitude $\left(M_{W}\right)$. b) Ratio of DJ- to MM-predicted nuclear yield at a given DOB and $\mathrm{M}_{\mathrm{W}}$. For chemical explosions this ratio should be multiplied by 2 , the observed chemical/nuclear factor needed to apply the nuclear-derived MM model to chemical explosions. 


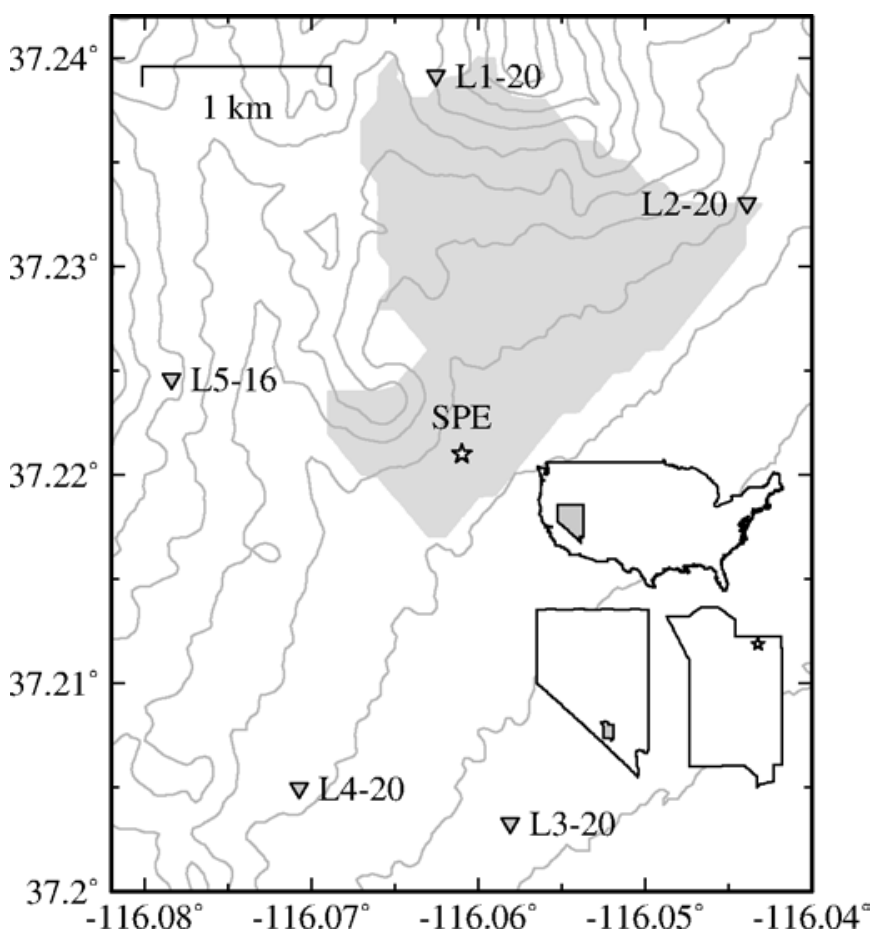

Figure 4 (map). Map of the Source Physics Experiments at Climax Stock in northern Yucca Flat at the Nevada National Security Site. Gray is granite outcrop. $50 \mathrm{~m}$ elevation contours. Inset is location. Inverted triangles are station locations at $2 \mathrm{~km}$ distance except L5-16 that is $1.6 \mathrm{~km}$ from the SPE epicenter. 

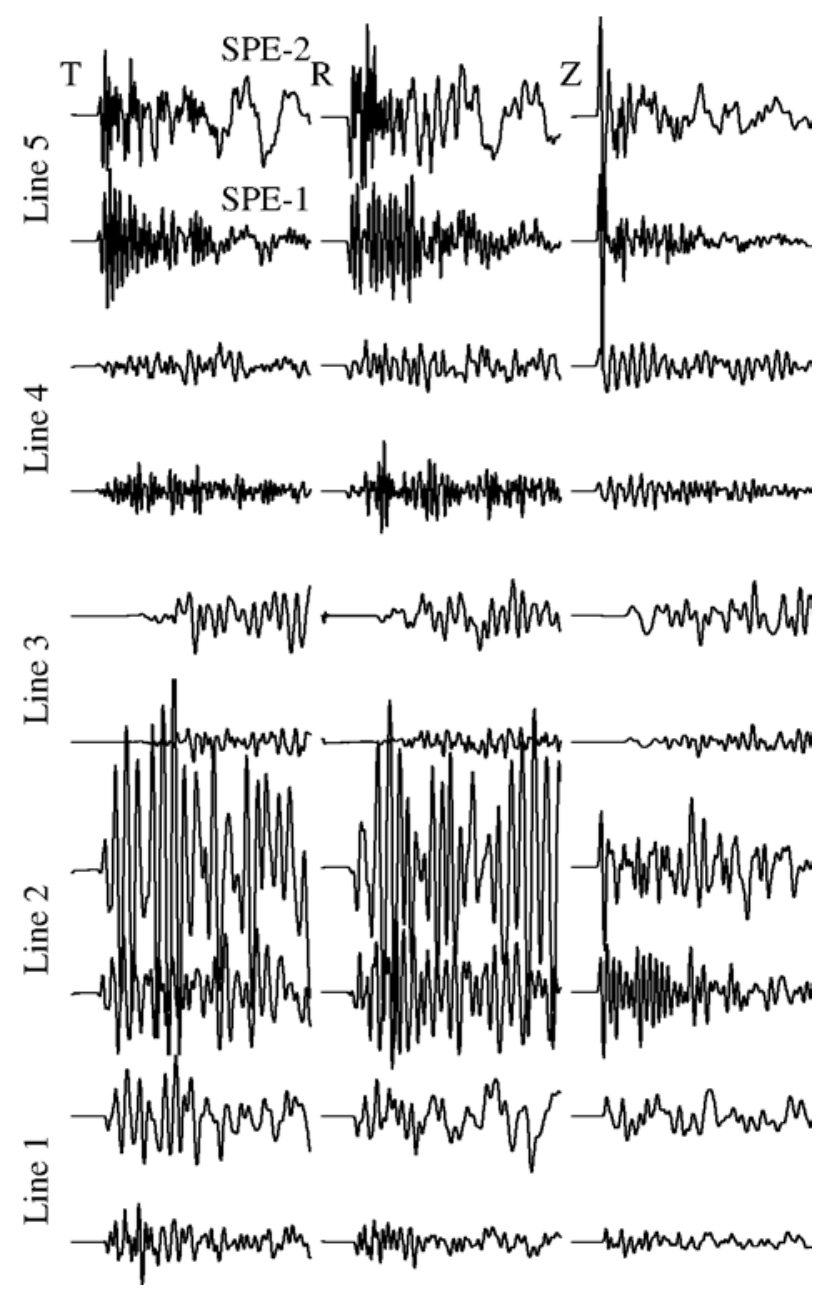

Figure 5 (waveDH). Recordings of SPE-1/-2 (bottom and top trace, respectively) at the stations shown in Figure 4. T, R, and Z refer to the transverse, radial, and vertical component, respectively. SPE-1 traces are multiplied by 4 and each trace is 1 sec long. 

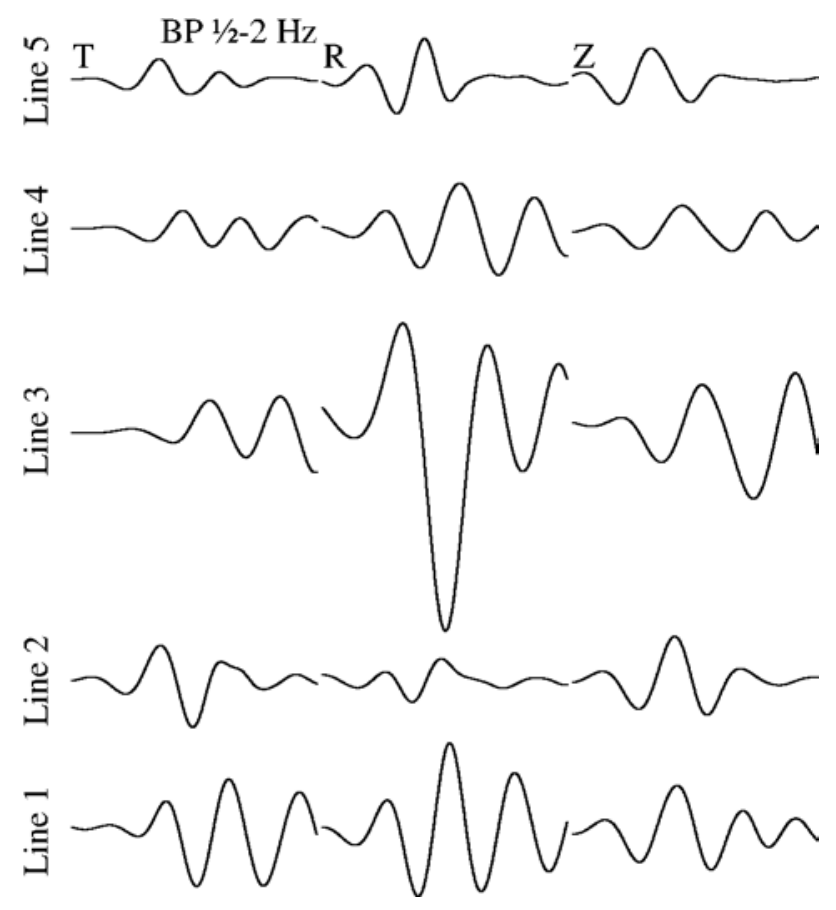

Figure 6 (waveBP). Recordings of SPE-2 at $2 \mathrm{~km}$ distant station for Lines 1-4 and $1.6 \mathrm{~km}$ distant station on Line 5. T, R, and Z refer to the transverse, radial, and vertical component, respectively. The raw records are bandpassed between $1 / 2$ and $2 \mathrm{~Hz}$. Each trace is 2 sec long. 


\section{Source Physics Experiment}

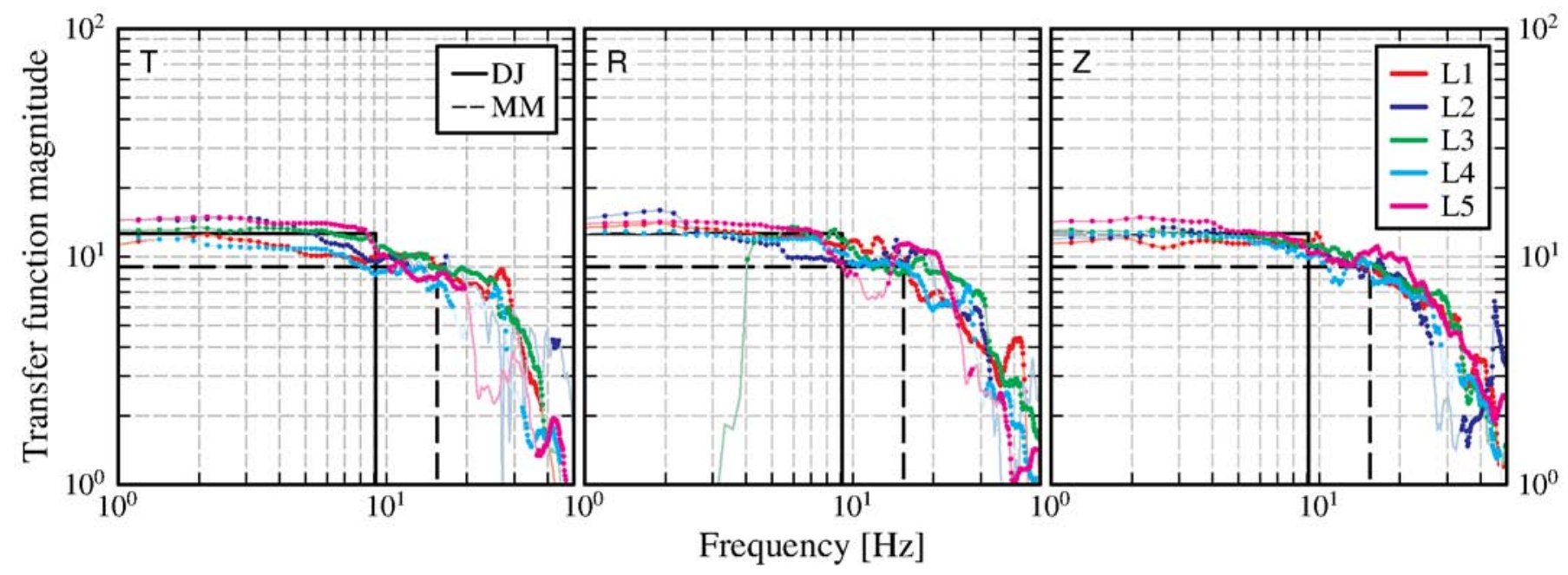

Figure 7 (specratspeDH). Transfer functions of the SPE-2/SPE- 1 at the $2 \mathrm{~km}$ distant station along each line (see Figure 4), except Line 5 which is at $1.6 \mathrm{~km}$. Spectral measurements with a coherence $>0.5$ are plotted with a circle. The DJ- (solid) and MM-predicted (dashed) ratios and corner-frequencies are also given where the near-source parameters are from Table 2. The corner frequency in the MM model assumes a chemical/nuclear yield factor of two. 


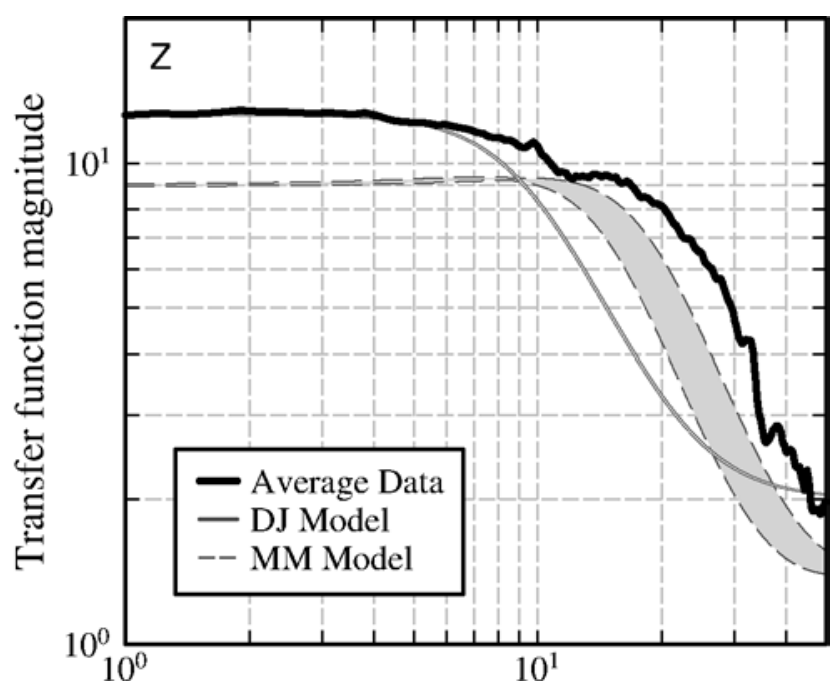

Figure 8 (specratspeDHmod). Coherence-weighted log-average of the vertical components compared with the DJ- (solid) and MM-predicted (dashed) transfer functions for the minimum and maximum of near-source parameters (shaded gray) given in Townsend et al. (2012) and discussed in the text. The MM model ratio assumes a chemical/nuclear yield factor of two, which changes the corner frequencies, but not the longperiod ratio where the difference is factored out. 


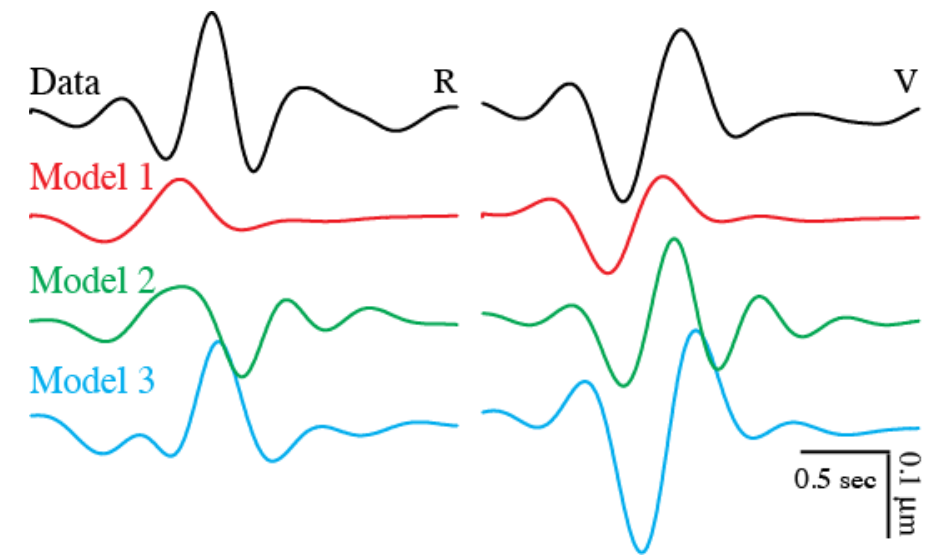

Figure 9 (exmtdj2). Low-frequency $(1 / 2-2 \mathrm{~Hz})$ displacement at $1.6 \mathrm{~km}$ distant station along Line 5 compared with DJ-predicted synthetics for three velocity models (see Table 4), where $\mathrm{R}$ and $\mathrm{V}$ are the radial and vertical component, respectively. 


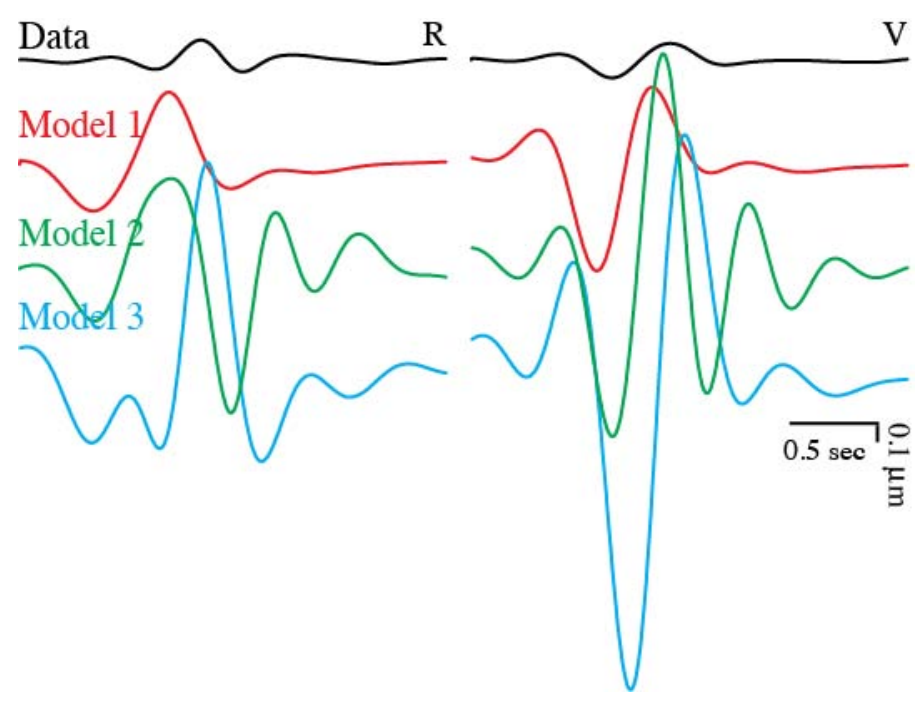

Figure 10 (exmtmm5). Low-frequency $(1 / 2-2 \mathrm{~Hz}$ ) displacement at $1.6 \mathrm{~km}$ distant station along Line 5 compared with MM-predicted synthetics, where chemical/nuclear factor of two is employed for three velocity models (see Table 3), where $\mathrm{R}$ and $\mathrm{V}$ are the radial and vertical component, respectively. 